\title{
The conservative physiology of the immune system
}

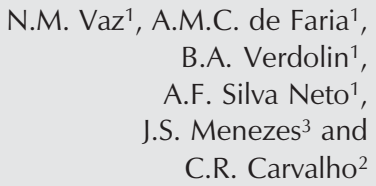

\author{
Departamentos de ${ }^{1}$ Bioquímica e Imunologia, and ${ }^{2}$ Morfologia, \\ Instituto de Ciências Biológicas, Universidade Federal de Minas Gerais, \\ Belo Horizonte, MG, Brasil \\ ${ }^{3}$ Departamento de Imunologia, Instituto de Ciências Biomédicas III, \\ Universidade de São Paulo, São Paulo, SP, Brasil
}

\section{Correspondence \\ N.M. Vaz \\ Departamento de Bioquímica e \\ Imunologia \\ ICB, UFMG \\ Caixa Postal 486 \\ 30161-970 Belo Horizonte, MG \\ Brasil \\ Fax: +55-31-3499-2640 \\ E-mail: nvaz@mono.icb.ufmg}

Research supported by CNPq (No. 520834/96-8) and CAPES/ICCTI

(No. 060/00). Publication

supported by FAPESP.

Received August 5, 2002

Accepted November 7, 2002

\begin{abstract}
Current immunological opinion disdains the necessity to define global interconnections between lymphocytes and regards natural autoantibodies and autoreactive $\mathrm{T}$ cells as intrinsically pathogenic. Immunological theories address the recognition of foreignness by independent clones of lymphocytes, not the relations among lymphocytes or between lymphocytes and the organism. However, although extremely variable in cellular/molecular composition, the immune system preserves as invariant a set of essential relations among its components and constantly enacts contacts with the organism of which it is a component. These invariant relations are reflected, for example, in the life-long stability of profiles of reactivity of immunoglobulins formed by normal organisms (natural antibodies). Oral contacts with dietary proteins and the intestinal microbiota also result in steady states that lack the progressive quality of secondary-type reactivity. Autoreactivity (natural autoantibody and autoreactive $\mathrm{T}$ cell formation) is also stable and lacks the progressive quality of clonal expansion. Specific immune responses, currently regarded as the fundament of the operation of the immune system, may actually result from transient interruptions in this stable connectivity among lymphocytes. More permanent deficits in interconnectivity result in oligoclonal expansions of $\mathrm{T}$ lymphocytes, as seen in Omenn's syndrome and in the experimental transplantation of a suboptimal diversity of syngeneic $\mathrm{T}$ cells to immunodeficient hosts, which also have pathogenic consequences. Contrary to theories that forbid autoreactivity as potentially pathogenic, the physiology of the immune system is conservative and autoreactive. Pathology derives from failures of these conservative mechanisms.
\end{abstract}

\section{Introduction}

Current immunological theories are based on the belief that: a) the immune system is composed of independent clones of lymphocytes which are generated at random; b) immunological activity consists of the ex-
Key words - Immunobiology

- Immune system

- Closure

- Network

- Autopoiesis

- Panama blot 
common denominator of immunopathology.

Contrary to these convictions: a) stable and previsible regularities, which cannot derive from random mechanisms, are present in the reactivity of immunoglobulins formed by normal organisms (natural autoantibodies) (1); b) these global patterns of reactivity change in autoimmune diseases $(2,3)$ and severe forms of chronic parasitic diseases $(4,5)$ in ways that cannot derive from unconnected specific immune responses to autoantigens or parasite antigens; c) abundant physiologic reactivity to body components is demonstrable in both B (1) and T lymphocytes $(6,7)$, and d) oligoclonal expansion of $\mathrm{T}$ lymphocytes, as we will discuss, may be a common denominator of a variety of, or maybe all, manifestations of immunopathology.

\section{Objective}

In this essay we have two objectives. The first is to formulate a question, rather than to supply answers to traditional questions. The question is: What must we observe to agree that we have reached an explanation of immunological phenomena? - not a particular phenomenon, but all of them, as a class of biological phenomena. Second, we want to suggest that immunopathology derives from derangements in lymphocyte connectivity rather than from antigen-driven specific immune responses.

\section{Explanations}

What must we observe to agree that we have reached an explanation of immunological phenomena? An explanation must contain a generative mechanism, i.e., a set of components and relations among these components, which operate to generate the phenomenon or the entity we want to explain (8). Which components, what set of relations must we observe to be able to say that a vertebrate organism has an immune system - a kind of system which is absent in invertebrate animals or plants?

Immunologists consensually agree that lymphocytes displaying clonally expressed receptor molecules with variable regions are essential components of immune systems. The presence of lymphocytes, therefore, is a marker of immunological activities. But do these lymphocyte clones act alone, independently from each other and from the organism? Or do they act in consonance among themselves and between themselves and the organism? If they act harmonically, how are these connections assembled in a system able to generate the phenomena we observe? And what is a "system" that we may call the immune system a system?

According to Maturana and Varela (8), "a system is any collection of elements which through their preferential interactions (among themselves) create an operational boundary that separates them from other elements with which they can also interact and that, thus, configure the medium in which such collection of elements (the system) operates as a totality. Thus, a system exists as a totality in a medium with which it interacts, and exists also in another domain: the structural domain, a space generated by the interactions among its components. As a totality, a system does not exist by itself: it exists in a medium in interactions which trigger structural changes in it. The system preserves its condition as a particular kind of system as long as the organization that defines it and constitutes it as a system (a compound unity) of that kind is preserved."

For this reason, a dynamic system can only exist in a medium that triggers in it structural changes through which the identity of the system is conserved. Thus, an immune system must be defined not only on the basis of the presence of lymphocytes, but also according to the way changes occur in the relations among these lymphocytes and between the lymphocytes and the organism while the system operates. 


\section{The organism as a medium}

From this viewpoint, the medium in which the immune system operates is the organism of which it is a component. The structural domain is an interactional space (8), a space generated by the interactions among lymphocytes, not the physical space provided by the organism. Also, as components of the immune system, lymphocytes always interact with the organism and never interact with components of the external medium in which the organism operates, which remains as a meta-medium for the immune system. Accordingly, only the organism may be said to contact foreign materials; for the immune system, there is no foreignness, no inside, no outside; self/nonself discrimination becomes a pseudo-problem.

This is a radical departure from the conventional way of thinking and, as such, may seem unacceptable. Are we to admit that the recognition of foreignness is no longer the basis of immune responsiveness? The major goal of immunological research has always been understanding the mechanism of specific immune responses. Immunological defense against foreign invaders is certainly essential for the conservation of health. How dare we disregard these notions?

Of course, it remains imperative to account for the importance of immune activities in the maintenance of health. It is true that germs are no longer seen as a threat of impending disaster, as in the Pasteurian view of infections. The ubiquity of microscopic living systems continues to surprise us. Viruses are the most common biological agents in clean ocean water, typically numbering ten billion per liter, and probably infect all marine organisms (9). The number of prokaryotic cells on the planet is estimated to be $4-6 \times 10^{30}(10)$, and an amazing variety of bacteria is found on the surfaces of organisms, for example, on the mammalian gut mucosa (11). On the other hand, germs and viruses have been involved in the mechan- isms of noninfectious diseases by triggering self-inflicted damage in the organism (12).

Contrary to the idea of a primarily defensive immune system, we may choose to see the organism as an entity structurally coupled to a medium in which it is realized as such organism. According to this view, the organism is no longer in opposition to a dangerous medium, and we may study the dynamics of this integration. We may see the medium as the realm that makes possible the living of organisms which, reciprocally, bring forth this particular medium.

\section{Two aspects of immunological activity}

Let us begin the approach to our most general question - What must we observe to agree that we are observing an immune system? - by pointing to two distinct aspects of immunological activity.

The generation of lymphocyte diversity is preserved in mice totally deprived of contact with foreign macromolecules. Germfree mice reared on a synthetic "antigen-free" diet ("antigen-free" mice) display serum IgG levels one-tenth those of germfree mice fed natural-type diet and one-hundredth those of SPF mice fed the natural-type diet, but their serum IgM is only slightly lower than that observed in germfree animals fed a naturaltype diet (13). Young and old antigen-free mice, although devoid of exogenous antigenic and/or mitogenic stimulation, generate B cells with a similar switching capacity and a similar IgM antibody specificity repertoire as conventional mice $(14,15)$. They also display patterns of reactivity which are indistinguishable from those observed in SPF or conventional mice (16). These antigen-free mice are grossly abnormal in several aspects of immune physiology; they lack mucosaassociated lymphoid tissue and may fail to develop mesenteric lymph nodes (15).

This demarcates two distinct aspects in immunological activity, one of which in- 
cludes the generation of lymphocyte diversity, IgM production and secretion, events that may occur in antigen-free mice and arise independently of antigenic contacts. Using the current jargon, we might call this the "innate" aspect of "adaptive" immunity. A second aspect, absent in antigen-free mice, includes the emergence of germinal center reactions in lymphoid tissues, in which $\mathrm{B}$ cells proliferate and switch immunoglobulin isotypes, starting the formation of $\operatorname{IgG}, \operatorname{IgA}$ and $\operatorname{IgE}(17)$. These modifications are generally associated with the development of secondary-type immunological responsiveness (immunological memory). This second aspect, therefore, arises during perturbations triggered by the contact with external antigens. A curious exception, worth mentioning, is the increase in IgG production during syngeneic pregnancy in antigen-free mice (15).

\section{Progressive clonal expansion}

Historically, the fundamental aspect of immunological operations is presumed to be the triggering of specific immune responses and the development of secondary-type responsiveness (memory). According to the clonal selection theory (18), these phenomena are interpreted as expressions of specific clonal expansions stimulated by the presence of foreign macromolecules. Molecular genetics has provided ample evidence for the random generation of lymphocyte receptors (19) and there is currently little interest in the description of "global", integrative mechanisms in the operation of lymphocytes. The idiotypic network theory (20) was a brave and isolated attempt to approach immunology from a systemic point of view; incomplete and ill-understood, the theory is now virtually forgotten (21).

Nevertheless, the progressive aspect of specific clonal expansion, typical of secondary immune responses (memory) and presumed to be the basis of the efficacy of vaccination, is absent from several aspects of immunological activity. It is notably absent from naturally activated $\mathrm{T}$ lymphocytes $(22,23)$ and also from B lymphocytes responsible for the production of natural autoantibodies (1).

The progressive quality of clonal expansion is also absent from antigen-specific lymphocytes of animals which have been previously exposed to the antigen by mucosal routes and then immunized by parenteral routes. When higher doses of antigen are used in the oral (or nasal) pretreatment, the animals respond feebly to subsequent parenteral immunizations and are said to be orally tolerant $(24,25)$. However, with lower doses of antigen, animals that become "partially tolerant" may form significant titers of specific antibodies upon parenteral immunizations, although lower than in control animals without mucosal pretreatment. And here is the relevant point: whereas control animals increase specific antibody titers at each additional injection of antigen, the titers of antibodies formed by "partially tolerant" mice remain remarkably stable in spite of repeated injections of antigen (26). Thus, "partially tolerant" animals have no secondary-type responsiveness (memory) and, at the same time, cannot be properly characterized as "tolerant", since they are forming significant amounts of specific antibodies. The reactivity to elements of the autochthonous microbiota is also stable (27) and something similar may be said of the physiologic production of autoantibodies, which remains stable in the presence of the specific autoantigens (1). Stability, not progressive responsiveness, is the distinctive mark of several physiologic aspects of immune responsiveness, e.g., those related to food intake, to the native microbiota and to autoreactivity.

Furthermore, the contact with dietary proteins may be immunologically important in ways that are not presently understood. We have recently demonstrated that chronic administration of a protein-free diet balanced with amino acids, starting at weaning, has 
profound effects on the immune system of mice (28). As might be predicted, animals raised on the amino acid diet have a marked reduction in gut-associated lymphoid tissues and mesenteric lymph nodes. However, they also display modifications in peripheral lymph nodes and, in a totally unexpected manner, in the thymus. The production of IgA and $\operatorname{IgG}$, but not of $\operatorname{IgM}$, is severely hindered (28), similarly to what is seen in antigen-free mice (13-15). Dietary proteins, therefore, in addition to being important for the gut flora, are important for the maintenance of an immunological "tonus" (11). This is of obvious relevance to clinical immunology.

In summary, the distinctive characteristic of immunological reactivity to body components, dietary proteins and elements of the gut flora is not the absence of reactivity, but rather the absence of progressive responsiveness. On the other hand, this progressive quality, which is characteristic of specific immune responses, is also associated with several manifestations of immunopathology.

\section{In search of a physiology}

In her outstanding description of the history of the gene as a source of biological constancy and variation, Fox Keller (29) stressed that neodarwinism is rather poor of hypotheses on the origin of constancy. Darwin himself complained about our ignorance not of the source, but of the laws of variation (30). The clonal selection of lymphocytes is an excellent example of neodarwinian mechanisms operating in the life of a single organism. As such, it points to the source, not the laws of variation and has nothing to say about regularities (constancy) in the operation of the immune system. Constancy would seem to be in the province of inherited (innate) mechanisms of defense (31), apparently incompatible with the flexible character of adaptive immunity. Flexibility, however, pertains to change but also to preserva- tion. Actually, change is only meaningful against a background of constancy.

In current immunology, the immune system is equal to the sum of its (clonal) parts. The concept of a complex dynamic "system", however, implies a set of invariant relations among certain components, an organization, i.e., relations that transcend structural variations. Systems may be understood as compound unities in which interference with one component affects other, eventually all components, and the relations among components are more important than the structure of individual components (8). The immune system is a fine example of a dynamic system in ceaseless structural variation. Amidst all this variation in which cellular and molecular components are continuously replaced, the emergence of constancy appears to be utterly improbable. And yet, there is constancy. The immune system is flexible, but not endlessly variable. It is more than the sum of its parts.

The evidence for regularities in the operation of the immune system, although presently slender, is far from insignificant and cannot be explained by the antigen-driven expansion of randomly generated lymphocyte clones. The search for regularities demands the development of new experimental methods, of which the Panama blot (see below) is just an initial, although important example. Even more important, however, is the opportunity to see the immune system in another way.

\section{Panama blots}

One of the problems in describing an immune system as a multiconnected network is how to develop methods able to deal with this global connectivity, as well as a language to describe it. A bold attempt in this direction was made by the inventors of the Panama blot assay (32-35), a method that inaugurates a new way of looking into immunological activity. A modified immuno- 
blot assay, the Panama blot, is not aimed at the detection or quantitation of a particular specific antigen-antibody reaction. It allows the semiquantitative comparison of patterns of global reactivity of natural serum immunoglobulins with complex antigenic mixtures previously separated by electrophoresis. Antigenic extracts consisting of autologous whole organs (brain, liver, muscle, etc.) or whole bacterial cultures (such as Escherichia coli) have been used. The reaction of serum immunoglobulins with these complex molecular mixtures allows the development of elaborate profiles of reactivity, which are used to compare patterns of different individuals, or different conditions of the same individual, rather than to detect or measure individual specific immunological reactions, as is customary in serology. In this sense, the Panama blot is not a "serological" method.

Panama blots lead to the characterization of four important aspects of the global reactivity of immunoglobulins. First, immunoglobulin profiles of reactivity were characteristic for each particular mouse strain and later shown to be affected by genes known to be important in immunological activities (35). Second, reactivity profiles developing early in ontogenesis were remarkably stable throughout life both in murine (36) and human immunoglobulins (37-39). This was most notable with IgM, but, to some extent, also applied to $\operatorname{IgG}$, especially with respect to autoreactive immunoglobulins (37).

The third aspect is most surprising and is of far-reaching consequences. No significant changes in Panama blots were seen in normal mouse IgM from mice maintained in germfree, or "antigen-free" conditions, i.e., germfree mice fed from birth with an elemental ultrafiltered, macromolecule-free diet. This suggested that the production of IgM is not affected by food antigens or the autochthonous microbiota, which are generally believed to be immunogenic stimuli involved in the generation of "natural" immunoglobulins (16). At the other end of the spectrum, hyperimmunized horses utilized as producers of therapeutic antisera against tetanus toxin, several distinct snake poisons and scorpion poison, displayed IgM profiles of reactivity against autologous organs (horse liver) and/or E. coli extracts not significantly different from those detected in normal nonimmunized horses (40).

There is a fourth important aspect: Panama blots undergo significant and characteristic changes during severe alterations of immunological activities, such as human autoimmune diseases (41-43). More recently, changes in Panama blot profiles against autologous organs and/or E. coli extracts were correlated with clinical forms of chronic parasitic diseases, such as trypanosomiasis cruzi, malaria and schistosomiasis mansoni, both in humans and in mice $(4,5,44)$.

Differently from other mouse strains, a severe form of schistosomiasis is observed in $20 \%$ of male, but not female, CBA/J mice, which is similar to the hepatosplenic form of the human disease (45). Results obtained with experimental schistosomiasis mansoni in CBA/J mice are particularly relevant because they point to the somatic generation of disease in a genetically homogeneous population. Variable clinical forms of schistosomiasis mansoni in mice and humans are associated with the production of characteristic immunoglobulin idiotypes (46). We have recently found that the majority of animals with the severe form of the disease may be identified by Panama blot profiles against mouse liver extracts (5).

\section{The emergence of pathology}

We now reach the second and last issue in this essay, namely, the possibility to describe common ground for immunopathology, derived from an imbalance in lymphocyte connectivity. Aberrant patterns of connectivity of the immune system are associated with autoimmune diseases, in which significant changes in the pattern of immu- 
noglobulin formation occur (41-43). When von Pirquet and Schick characterized "serum sickness", they showed that immunological activities, of themselves, are not always "defensive" and may be damaging to the organism (47). Soon thereafter, von Pirquet introduced the term "allergy" to represent this "other form" of operation of immune mechanisms. The unbalanced operation of parcels of the immune system, therefore, differently from its integrated operation, may inflict damage to the organism in the same way that failures in neuromuscular coordination can make us bite the tongue, pull a muscle or kill us by asphyxia.

A deficiency in the connectivity among lymphocytes may lead to pathogenic oligoclonal expansion of T lymphocytes, as shown several years ago by Sakaguchi (48). Mice thymectomized soon after birth remain immunodeficient, but thymectomy of 3-dayold mice results in autoimmune lesions, which may be prevented by the implant of a thymus graft. "Experiments of nature", as Robert Good would say, point in the same direction, as demonstrated by the Omenn's syndrome. Human newborns with severe combined immunodeficiency remain immunologically incompetent, whereas newborns with less severe mutations in Rag-1 or Rag-2 develop Omenn's syndrome, characterized by the oligoclonal activation of $\mathrm{T}$ lymphocytes, hypereosinophilia and high levels of $\operatorname{IgE}(49)$.

A survey of medical databases may supply a large number of examples, too large to be quoted here, in which the oligoclonal expansion of $\mathrm{T}$ lymphocytes seems to be involved in immunopathology.

All this indicates that the physiology of the immune system is conservative and offers great resistance to changes in its patterns of activity. Of course, in order to accept this idea, one must first be willing to accept that it is possible to describe a global organization for the immune system, which is reflected in the preservation of patterns of activity.
This preservation is expressed not only in the patterns of natural immunoglobulins and their deviation in severe diseases, but also in phenomena related to "oral tolerance", which are the tip of an iceberg floating in this direction. Historically associated with medicine and bacteriology, the study of immunology has emphasized pathological changes of the immune system and neglected the constancy of its physiology. Maybe the time to change this attitude has arrived.

Support for this interpretation may be also sought in the experimental work carried out in Antonio Coutinho's laboratory about ten years ago, with the theoretical support of John Stewart and the late Francisco Varela. Theory predicted that while total immunoglobulin levels in serum are kept constant, the concentrations of specific "natural antibodies" should fluctuate in time around an attractor with characteristic "chaotic" dynamics (50-53). After developing tools to follow individual V-region idiotypes in normal sera, experiments were performed to test this prediction. Indeed, natural antibody concentrations did fluctuate in a time-dependent manner, mostly over ten-fold. Furthermore, the intravenous injection of sub-microgram amounts of natural antibodies in saline was a sufficient "perturbation" to result in specific "compensations" in the concentrations of complementary antibodies and in marked alterations in the dynamics of the respective time-dependent fluctuations (54-56). Moreover, the dynamics of "natural antibody fluctuations" in individuals suffering from autoimmune diseases revealed differences from healthy organisms and, in some cases, normal patterns could be restored by the infusion of normal immunoglobulins (57). It looked as though the system had lost its characteristic "chaotic" behavior, rich in evolutive possibilities, to be fixed in "noisy" or cyclic dynamics (58). This seemed to provide a distinctive characteristic between health and disease. However, only a small number of points could be produced in the 
necessary serial evaluations due to the limitations of repeatedly bleeding men or mice. This leads to a postponement of these experiments until the appropriate technology becomes available, a situation which may be resolved in the near future.

\section{Coda}

The physiology of the immune system is conservative and maintains steady states of lymphocyte activation and differentiation acquired early in ontogenesis, influenced but not determined by maternal and early environmental factors, as revealed by the ontogeny of patterns of natural IgM reactivity with complex antigenic mixtures (40-43). We propose that clonal expansions occurring during infectious, allergic and autoimmune diseases are elements inherent to the pathology of these conditions, which may be better described as deviations from normal dynamics than as defensive reactions. Even from a traditional viewpoint, allergic and autoimmune diseases may both be seen as issues of deviant and/or excessive clonal responsiveness. On the other hand, the par- ticipation of immunological activities in infectious diseases has always been described as defensive. Immunodeficient organisms are easy prey to infectious aggressions. Defense, however, is a legitimate definition of the result of body activities but, as such, it belongs to our comments as observers, and does not belong to the molecular/cellular/ organic dynamics of living. This is not to deny that immunological activities participate in the dynamics of infectious diseases, but rather to claim that these activities lack the directionality necessary to qualify them as defensive.

The conservative physiology of the immune system generates stable levels of specific antibody formation to body components and also to dietary proteins. Primed syngeneic lymphocytes transferred to normal adult recipient mice, followed by a parenteral boost with the antigen, respond poorly, due to a "syngeneic barrier", which builds up steadily during ontogeny and may be broken by irradiation (59). This "barrier" may be reinforced by first rendering the recipient animals orally tolerant to the specific antigen (60).

\section{References}

1. Coutinho A, Kazatchkine MD \& Avrameas S (1995). Natural autoantibodies. Current Opinion in Immunology, 7: 812-818.

2. Coutinho A \& Haas W (2001). In vivo models of dominant T-cell tolerance: where do we stand today? Trends in Immunology, 22: 350-351.

3. Coutinho A, Hori S, Carvalho T, Caramalho I \& Demengeot J (2001). Regulatory $\mathrm{T}$ cells: the physiology of autoreactivity in dominant tolerance and "quality control" of immune responses. Immunological Reviews, 182: 89-98.

4. Vaz N, Silva Neto AF, Coelho A, Correa-Oliveira R, Braga E \& Fesel C (2000). Perfis de IgM e IgG naturais em parasitoses crônicas humanas graves. XV Annual Meeting of the Federação de Sociedades de Biologia Experimental, Caxambu, MG, Brazil, August 23-26, 2000. 166 (Abstract 29.007).

5. Vaz N, Fesel C, Nobrega A, Silva Neto AF, Secor WE \& Colley DG (2001). Severity of schistosomiasis mansoni in male CBA mice is related to IgG profiles reacting with mouse liver extracts in Panamablots. XVI Annual Meeting of the Federação de Sociedades de Biologia Experimental, Caxambu, MG, Brazil, August 29 - September 1, 2001. 136 (Abstract 24.003)
6. Pereira P, Larsson EL, Forni L, Bandeira A \& Coutinho A (1985). Natural effector $T$ lymphocytes in normal mice. Proceedings of the National Academy of Sciences, USA, 82: 7691-7695.

7. Modigliani Y, Coutinho A, Pereira P, Le Douarin N, Thomas-Vaslin V, Burlen-Defranoux O, Salaun J \& Bandeira A (1996). Establishment of tissue-specific tolerance is driven by regulatory $T$ cells selected by thymic epithelium. European Journal of Immunology, 26: 18071815.

8. Maturana H \& Varela F (1980). Autopoiesis and Cognition. The Realization of the Living. Reidel, Dordrecht, The Netherlands.

9. Fuhrman JA (1999). Marine viruses and their biogeochemical and ecological effects. Nature, 399: 541-548.

10. Whitman WB, Coleman DC \& Wiebe WJ (1998). Prokaryotes: The unseen majority. Proceedings of the National Academy of Sciences, USA, 95: 6578-6583.

11. Bocci $\vee$ (1992). The neglected organ: bacterial flora has a crucia immunostimulatory role. Perspectives in Biology and Medicine, 52: 251-260.

12. De Vries RR, Cohen IR \& van Rood JJ (1990). The Role of MicroOrganisms in Noninfectious Diseases. Springer Verlag, New York, 
NY, USA.

13. Hashimoto K, Handa H, Umehara K \& Sasaki S (1978). Germfree mice reared on an "antigen-free" diet. Laboratory Animal Science, 28: $38-45$.

14. Hooijkaas $H$, van der Linde-Preesman $A A$, Bitter WM, Benner $R$, Pleasants JR \& Wostmann BS (1985). Frequency analysis of functional immunoglobulin $\mathrm{C}$ - and $\mathrm{V}$-gene expression by mitogen-reactive $B$ cells in germfree mice fed chemically defined ultra-filtered "antigen-free" diet. Journal of Immunology, 134: 2223-2227.

15. Bos NA, Benner R, Wostmann BS \& Pleasants JR (1987). "Background" Ig-secreting cells in pregnant germfree mice fed a chemically defined ultrafiltered diet. Journal of Reproductive Immunology, 9: $237-246$.

16. Haury M, Sundblad A, Grandien A, Barreau C, Coutinho A \& Nobrega A (1997). The repertoire of serum IgM in normal mice is largely independent of external antigenic contact. European Journal of Immunology, 27: 1557-1563.

17. Camacho SA, Kosco-Vilbois MH \& Berek C (1998). The dynamic structure of the germinal center. Immunology Today, 19: 511-514.

18. Burnet MF (1959). The Clonal Selection Theory of Immunity. The Vanderbilt and Cambridge University Presses, Nashville, TN, USA and London, England.

19. Tonegawa S (1995). Somatic generation of antibody diversity. In: Gallagher RB, Gilder J, Nossal GJV \& Salvatore G (Editors), Immunology. The Making of a Modern Science. Academic Press, San Diego, CA, USA, 145-162.

20. Jerne NK (1974). Towards a network theory of the immune system. Annals of Immunology, 125C: 373-389.

21. Coutinho A (1995). The network theory: 21 years later. Scandinavian Journal of Immunology, 42: 3-8.

22. Larsson EL, Gullberg M, Bandeira A \& Coutinho A (1984). Activation and growth requirements for cytotoxic and noncytotoxic $T$ lymphocytes. Cellular Immunology, 89: 223-231.

23. Rocha BB (1987). Population kinetics of precursors of IL 2-producing peripheral T lymphocytes: evidence for short life expectancy, continuous renewal, and post-thymic expansion. Journal of Immunology, 139: 365-372.

24. Faria AM \& Weiner HL (1999). Oral tolerance: mechanisms and therapeutic applications. Advances in Immunology, 73: 153-264.

25. Vaz NM, Faria AMC, Verdolin BA \& Carvalho CR (1997). Immaturity, ageing and oral tolerance. Scandinavian Journal of Immunology, 46: 225-229.

26. Verdolin BA, Ficker SM, Faria AMC, Vaz NM \& Carvalho CR (2001). Stabilization of serum antibody responses triggered by initial mucosal contact with the antigen independently of oral tolerance induction. Brazilian Journal of Medical and Biological Research, 34: $211-$ 219.

27. Duchmann R, Schmitt $E$, Knolle $P$, Meyer zum Büschenfelde $K-H$ \& Neurath M (1996). Tolerance towards resident intestinal flora in mice is abrogated in experimental colitis and restored by treatment with interleukin-10 or antibodies to interleukin-12. European Journal of Immunology, 26: 934-938.

28. Menezes JS, Mucida DS, Cara DC, Alvarez-Leite JI, Russo M, Vaz NM \& Faria AMC (2001). Changes in the murine gut-associatedlymphoid tissue in the absence of food proteins. 11th International Congress of Immunology (ICI), Stockholm, Sweden, August 2000. 101 (W 4.20).

29. Fox Keller E (2000). The Century of the Gene. Harvard University Press, Cambridge, MA, USA, 12-13.

30. Darwin CR (1859). On the Origin of Species. Reprinted: 1964; Harvard University Press, Cambridge, MA, USA.
31. Janeway Jr CA \& Medzhitov R (2002). Innate immune recognition. Annual Review of Immunology, 20: 197-216.

32. Nobrega A, Haury M, Grandien A, Malanchere E, Sundblad A \& Coutinho A (1993). Global analysis of antibody repertoires. II. Evidence for specificity, self-selection and the immunological "homunculus" of antibodies in normal serum. European Journal of Immunology, 23: 2851-2859.

33. Haury M, Grandien A, Sundblad A, Coutinho A \& Nobrega A (1994). Global analysis of antibody repertoires. I. An immunoblot method for the quantitative screening of a large number of reactivities. Scandinavian Journal of Immunology, 39: 79-87.

34. Lacroix-Desmazes S, Kaveri S, Mouthon L, Ayouba A, Malanchere E, Coutinho A \& Kazatchkine MD (1998). Self-reactive antibodies (natural autoantibodies) in healthy individuals. Journal of Immunological Methods, 216: 117-137.

35. Vasconcellos R, Nobrega A, Haury M, Viale AC \& Coutinho A (1998). Genetic control of natural antibody repertoires: I. IgH, MHC and TCR beta loci. European Journal of Immunology, 28: 1104-1115.

36. Nobrega A, Haury M, Gueret R, Coutinho A \& Weksler ME (1996). The age-associated increase in autoreactive immunoglobulins reflects a quantitative increase in specificities detectable at lower concentrations in young mice. Scandinavian Journal of Immunology, 44: 437-443.

37. Lacroix-Desmazes S, Mouthon L, Coutinho A \& Kazatchkine MD (1995). Analysis of the human natural IgG antibody repertoire: lifelong stability of reactivities toward self-antigens contrasts with agedependent diversification of reactivities against bacterial antigens. European Journal of Immunology, 25: 2598-2604.

38. Lacroix-Desmazes S, Mouthon L, Kaveri SV, Kazatchkine MD \& Weksler ME (1999). Stability of natural self-reactive antibody repertoires during aging. Journal of Clinical Immunology, 19: 26-34.

39. Mouthon L, Lacroix-Desmazes S, Nobrega A, Barreau C, Coutinho A \& Kazatchkine MD (1996). The self-reactive antibody repertoire of normal human serum IgM is acquired in early childhood and remains conserved throughout life. Scandinavian Journal of Immunology, 44: 243-251.

40. Silva Neto AF (2000). Desenvolvimento ontogenético do repertório de anticorpos no modelo equino. Master's thesis, Universidade Federal de Minas Gerais, Belo Horizonte, MG, Brazil.

41. Ferreira $C$, Mouthon L, Nobrega A, Haury M, Kazatchkine MD, Ferreira E, Padua F, Coutinho A \& Sundblad A (1997). Instability of natural antibody repertoires in systemic lupus erythematosus patients, revealed by multiparametric analysis of serum antibody reactivities. Scandinavian Journal of Immunology, 45: 331-341.

42. Sundblad A, Ferreira C, Nobrega A, Haury M, Ferreira E, Padua F \& Coutinho A (1997). Characteristic generalized alterations of autoantibody patterns in idiopathic thrombocytopenic purpura. Journal of Autoimmunity, 10: 193-201.

43. Sharshar T, Lacroix-Desmazes S, Mouthon L, Kaveri S, Gajdos P \& Kazatchkine MD (1998). Selective impairment of serum antibody repertoires toward muscle and thymus antigens in patients with seronegative and seropositive myasthenia gravis. European Journal of Immunology, 28: 2344-2354.

44. Santos-Lima EC, Vasconcellos R, Reina-San-Martin B, Fesel C, Cordeiro-Da-Silva A, Berneman A, Cosson A, Coutinho A \& Minoprio $P$ (2001). Significant association between the skewed natural antibody repertoire of Xid mice and resistance to Trypanosoma cruzi infection. European Journal of Immunology, 31: 634-645.

45. Freeman Jr GL, Montesano MA, Secor WE, Colley DG, Howard MJ \& Bosshardt SC (1996). Immunopathogenesis and immunoregulation in schistosomiasis. Distinct chronic pathologic syndromes in 
CBA/J mice. Annals of the New York Academy of Sciences, 797: 151-165.

46. Montesano MA, Freeman Jr GL, Gazzinelli G \& Colley DG (1990). Expression of cross-reactive, shared idiotypes on anti-SEA antibodies from humans and mice with schistosomiasis. Journal of Immunology, 145: 1002-1008.

47. Silverstein AM (2001). Autoimmunity versus horror autotoxicus: the struggle for recognition. Nature Immunology, 2: 279-281.

48. Sakaguchi S (2000). Regulatory T cells: key controllers of immunologic self-tolerance. Cell, 101: 455-458.

49. Villa A, Bozzi F, Sobacchi C, Strina D, Fasth A, Pasic S, Notarangelo LD \& Vezzoni P (2000). Prenatal diagnosis of RAG-deficient Omenn syndrome. Prenatal Diagnosis, 20: 56-59.

50. Vaz NM \& Varela FJ (1978). Self and non-sense: an organismcentered approach to immunology. Medical Hypotheses, 4: 231267.

51. Varela FJ, Coutinho A, Dupire B \& Vaz NM (1988). Cognitive networks: immune, neural and otherwise. In: Perelson AS (Editor), Theoretical Immunology. Vol. II. Addison-Wesley, Redwood City, CA, USA, 359-374.

52. Stewart J, Varela FJ \& Coutinho A (1989). The relationship between connectivity and tolerance as revealed by computer simulation of the immune network: some lessons for an understanding of autoimmunity. Journal of Autoimmunity, 2: 15-23.

53. Stewart J \& Varela FJ (1989). Exploring the meaning of connectivity in the immune network. Immunological Reviews, 110: 37-61.
54. Lundkvist I, Coutinho A, Varela FJ \& Holmberg D (1989). Evidence for a functional idiotypic network among natural antibodies in normal mice. Proceedings of the National Academy of Sciences, USA, 86: 5074-5078.

55. Stewart J \& Varela FJ (1990). Dynamics of a class of immune networks. II. Oscillatory activity of cellular and humoral components. Journal of Theoretical Biology, 144: 103-115.

56. Varela FJ, Andersson A, Dietrich G, Sundblad A, Holmberg D, Kazatchkine M \& Coutinho A (1991). Population dynamics of natural antibodies in normal and autoimmune individuals. Proceedings of the National Academy of Sciences, USA, 88: 5917-5921.

57. Dietrich G, Varela FJ, Hurez V, Bouanani M \& Kazatchkine MD (1993). Selection of the expressed B cell repertoire by infusion of normal immunoglobulin $\mathrm{G}$ in a patient with autoimmune thyroiditis. European Journal of Immunology, 23: 2945-2950.

58. Calenbuhr V, Bersini H, Stewart J \& Varela FJ (1995). Natural tolerance in a simple immune network. Journal of Theoretical Biology, 177: 199-213.

59. Celada $F$ (1966). Quantitative studies of the adoptive immunological memory in mice. I. An age-dependent barrier to syngeneic transplantation. Journal of Experimental Medicine, 111: 1-14.

60. Miller SD \& Hanson DG (1979). Inhibition of specific immune responses by feeding protein antigens. IV. Evidence for tolerance and specific active suppression of cell-mediated responses to ovalbumin. Journal of Immunology, 123: 2344-2350. 